\title{
ATRIBUTOS CORPORATIVOS E CONCENTRAÇÃO ACIONÁRIA NO BRASIL
}

\section{RESUMO}

Este artigo enfoca os possíveis determinantes da concentração do direito de voto e do direito sobre o fluxo de caixa por parte dos acionistas controladores das companhias abertas brasileiras. A análise investiga se variáveis endógenas das firmas e setoriais fazem com que al gumas empresas tenham estrutura de propriedade mais concentrada do que outras submetidas ao mesmo ambiente contratual. Ao se aplicarem testes empíricos a um painel com 161 empresas entre os anos de 1998 e 2002, as variáveis testadas como possíveis determinantes não parecem influenciar a concentração acionária dos controladores das empresas analisadas. Os resultados oferecem evidência em favor da hipótese de influência da exogeneidade da estrutura de propriedade sobre o desempenho corporativo, adotada em trabalhos recentes.

\section{Alexandre Di Miceli da Silveira \\ FEA-USP}

\section{Lucas Ayres B. de C. Barros}

Mackenzie

\section{Rubens Famá}

PUC-SP

\footnotetext{
ABSTRACTT his article focuses on the possible determinants of the concentration of the right to vote and the rights over cash-flow of the controlling shareholders of publicly-quoted Brazilian companies. The analysis investigates if endogenous variables of firms and sectors mean that some companies have a more concentrated corporate structure than others that undergo the same contractual environment. When empirical tests were applied to a panel of 161 companies between 1998 and 2002, the variables that were tested as possible determinants seem not to have an influence on the shareholder concentration of the owners of the companies that were analyzed. The results offer evidence in favor of the hypothesis of the influence of the exogeneity of the owner ship structure on corporate performance, which has been used in recent work.
}

PALAVRAS-CHAVE Estrutura de propriedade, governança corporativa, proteção ao investidor, direito de voto, direito sobre o fluxo de caixa.

KEYMORD 0 wnership structure, corporate governance, investor protection, voting rights, rights over cash-flow. 


\section{INTRODUÇÃO}

Os mecanismos de governança corporativa são instrumentos para a minimização dos custos decorrentes do problema de agência, isto é, são ferramentas para minimizar a perda de valor de mercado oriunda de conflitos de interesse entre tomadores de decisão e investidores de uma empresa. A estrutura de propriedade é um dos princípios por meio dos quais os gestores podem ser disciplinados, como: a estrutura de capital; a estrutura do Conselho de Administração; a política de compensação dos gestores; a competição no mercado de produtos; e o mercado de aquisições hostis.

A maioria dos estudos iniciais sobre estrutura de propriedade visava avaliar a influência deste mecanismo sobre o desempenho das empresas, como os estudos de Demsetz e Lehn (1985), Morck e outros (1988), McConnel e Servaes (1990) e Hermalin e Weisbach (1991). Em linhas gerais, os resultados destes estudos mostraram relação positiva significante e não monotônica ou não significante entre concentração da propriedade e desempenho corporativo. Uma linha de pesquisa desenvolvida por La Porta e outros (1998) passou a aval iar como a estrutura de propriedade das empresas varia entre os países, partindo da hipótese de que o el emento decisivo para a explicação das diferenças entre os sistemas de governança seria 0 grau de proteção legal oferecido aos investidores contra a expropriação pelos gestores e acionistas controladores. É possível, entretanto, que empresas dentro de um mesmo país apresentem níveis diferentes de concentração da propriedade devido a características intrínsecas das mesmas ou do seu setor de atividade (DEMSETZ, LEHN, 1985).

$O$ presente trabalho investiga atributos corporativos ou setoriais como determinantes da concentração do direito de controle (percentual de ações ordinárias) e do direito sobre o fluxo de caixa (percentual total deações) nas mãos dos controladores das companhias abertas brasileiras, utilizando um painel de empresas observadas entre os anos de 1998 e 2002. Alternativamente, verifica-se se as medidas de concentração acionária são mais adequadamente caracterizadas como variáveis aproximadamente exógenas, ou seja, não determinadas por quaisquer características da empresa ou do seu setor de atividade.

A próxima seção apresenta uma revisão das proposições teóricas que serviram como base para este estudo. Em seguida, detal ha-se o método empírico de pesquisa, incluindo-se a descrição das variáveis utilizadas, das hipóteses, do método estatístico e da amostra. Os principais resultados obtidos são então apresentados e descritos. A última seção traz as considerações finais do trabal ho.

\section{REVISÃO DE CONCEITOS}

A estrutura de propriedade das empresas pode emergir como resposta de equilíbrio ao ambiente legal em que operam. A análise da relação entre finanças e proteção legal aos investidores ganhou destaque com pesquisas de autores como La Porta e outros (1999, 2000), Claessens e outros (2002) e Beck e outros (2001), sugerindo que as diferenças nas leis e na garantia de sua aplicação entre os países causam diferenças na estrutura de propriedade, política de dividendos, disponibilidade de recursos externos e valorização dos papéis das empresas. A maior parte da literatura sobre as diferenças de estrutura de propriedade compara empresas entre países, buscando avaliar se a diferença na proteção ao investidor em ambientes contratuais distintos acarreta maior concentração da estrutura de propriedade.

No entanto, empresas de um mesmo país podem apresentar diferentes níveis de concentração da propriedade devido a características intrínsecas a elas ou ao seu setor de atividade. Demsetz e Lehn (1985) estiveram entre os pioneiros a trabalhar com esta possibilidade, postulando um modelo empírico no qual determinadas características das empresas ou dos setores em que atuam, como tamanho, risco e regulação do setor, poderiam ser determinantes do grau de concentração acionária. Argumentaram que a relação de causalidade da estrutura de propriedade sobre o desempenho seria potencial mente espúria, uma vez que a concentração da propriedade poderia ser uma variável endógena determinada pelas características das empresas. No Brasil, Okimura (2003) e Araújo Filho e outros (2003) apresentaram estudos similares ao de Demsetz e Lehn (1985).

A linha de pesquisa de Demsetz e Lehn (1985) foi retomada por Himmelberg e outros (1999), que estenderam seus resultados utilizando dados em painel e novas variáveis explanatórias para a concentração da propriedade. Os autores propõem que a proteção ao investidor, além de possuir um componente externo relacionado ao ambiente legal em que a empresa está inserida, possui um componente interno relacionado ao tipo de atividade empreendida e a outras características da companhia. Desta forma, a concentração da propriedade não ocorreria apenas em razão da proteção legal do investidor, mas também em razão da proteção ao investidor intrínseca à empresa, diferente para empresas submetidas a um mesmo ambiente contratual.

Entre os atributos citados por Himmelberg e outros (1999) como potenciais determinantes da estrutura de propriedade, três se destacam: o tamanho da companhia; 0 
escopo para gastos definidos pelo livre-arbítrio do gestor; e o risco idiossincrático da empresa. Segundo os autores, o tamanho possuiria um efeito incerto de antemão sobre a concentração da propriedade. Por um lado, os custos de agência e monitoramento poderiam ser maiores nas empresas grandes, aumentando a necessidade de concentração da estrutura de propriedade. Por outro, grandes empresas poderiam lançar mão de economias de escala de monitoramento da alta gestão utilizando, por exemplo, agências de rating, o que levaria a menor nível ótimo de concentração da propriedade. Com relação ao escopo para gastos definidos pel o livre-arbítrio do gestor, Himmelberg e outros (1999) argumentam que, como os investimentos em ativos fixos são observáveis e mais fáceis de monitorar, empresas com maior proporção de ativos fixos deveriam em geral apresentar menor nível ótimo de concentração da propriedade por apresentarem maior proteção intrínseca ao investidor.

N as empresas com el evada proporção de ativos intangíveis, ocorreria o contrário; a al ta concentração da propriedade poderia funcionar como compensação pela maior dificuldade de monitoramento dos gestores. Por fim, com relação ao risco idiossincrático da empresa, Himmel berg e outros (1999) argumentam que uma concentração maior da propriedade implica uma carteira menos diversificada por parte dos controladores. Logo, quanto maior for 0 risco específico ou diversificável da empresa, menor será o nível ótimo de concentração da propriedade.
Com base na literatura sobre governança corporativa e estrutura de propriedade, especialmente os estudos de Demsetz e Lehn (1985) e Himmelberg e outros (1999), destacam-se os seguintes determinantes potenciais da concentração da estrutura de propriedade: escopo para gastos definidos pel o livre-arbítrio do gestor ou natureza da operação da empresa; tamanho da empresa; nível do fluxo de caixa livre; taxa de investimento; risco idiossincrático; desempenho corporativo; setor de atividade; e tipo do acionista controlador.

Os determinantes potenciais da estrutura de capital são variáveis relacionadas à proteção ao investidor em nível corporativo, já que a hipótese central dos trabal hos que serviram como base teórica para este artigo é de que quanto mais frágil for a proteção aos investidores - não apenas no âmbito legal, mas também no nível corporativo -, maior será a concentração da propriedade. As proposições teóricas envolvendo cada determinante são apresentadas no Quadro 1.

\section{MÉTODO DE PESQUISA}

A anál ise estatística realizada compreende regressões utilizando o método dos M ínimos Quadrados Ordinários e os procedimentos de Efeitos Fixos e Efeitos Aleatórios aplicados a um painel de empresas observadas entre os anos de 1998 e 2002. Sugere-se que a concentração acionária

Quadro 1 - Determinantes potenciais da concentração da estrutura de propriedade e controle

(continua)
DETERM INANTE POTEN-
CIAL DA CONCENTRA-
ÇÃO DA PROPRIEDADE
JUSTIFICATIVA
Natureza da Operação
Himmelberg e outros (1999) argumentam que empresas com ativos mais difíceis de monitorar (maior proporção de intangíveis) apresentarão maior concentração da pro- priedade por parte do controlador como forma de compensar a baixa proteção ao in- vestidor intrínseca à empresa
Porte da Empresa
Para Himmelberg e outros (1999), a concentração da propriedade em empresas maio- res tende a ser menor, pois os investidores podem ter acesso à melhor proteção (ex: economias de escala para monitoramento). Ademais, a proporção do valor da empresa em relação à riqueza individual dos controladores é maior, tornando-se mais difícil para eles manter uma proporção elevada do capital total à medida que a empresa cresce. Por outro lado, empresas grandes podem estar sujeitas a maiores problemas de agência, induzindo a uma concentração maior da propriedade

CÓDIGO DA

VARIÁVEL

TANG 
(conclusão)

\begin{tabular}{|c|c|c|}
\hline $\begin{array}{l}\text { Nível do Fluxo de Caixa } \\
\text { Livre }\end{array}$ & $\begin{array}{l}\text { Conforme sugerido por Jensen (1986), quanto maior for o fluxo de caixa livre (FCL), maior } \\
\text { será o gasto definido pelo livre-arbítrio do insider (gestor/ empreendedor) e, portanto, } \\
\text { maiores serão os benefícios privados potenciais do controle na forma, por exemplo, de } \\
\text { mordomias e de privilégios. Logo, um aumento do FCL elevaria a concentração da pro- } \\
\text { priedade desejada pelo controlador }\end{array}$ & $\mathrm{FCL} / \mathrm{REC}$ \\
\hline Taxa de Investimento & $\begin{array}{l}\text { Similarmente à variável anterior, quanto maior for a taxa de investimento da empresa, } \\
\text { maior será o gasto a ser definido pelo livre-arbítrio do gestor e/ ou empreendedor e maior } \\
\text { deve ser a concentração da propriedade desejada por ele (DEMSETZ,LEHN, 1985; HIM- } \\
\text { MELBERG e outros, 1999) }\end{array}$ & I/K \\
\hline $\begin{array}{l}\text { Risco Idiossincrático da } \\
\text { Empresa }\end{array}$ & $\begin{array}{l}\text { Maior concentração da propriedade implica uma carteira menos diversificada dos con- } \\
\text { troladores. Portanto, segundo Himmelberg e outros (1999), quanto maior for o risco } \\
\text { idiossincrático da empresa, menor deverá ser a concentração da propriedade desejada } \\
\text { por eles, pois o risco idiossincrático torna mais cara a posse de ações da empresa por } \\
\text { parte de grandes acionistas }\end{array}$ & IDIOS \\
\hline \multirow[t]{2}{*}{ Desempenho (DESEMP) } & \multirow[t]{2}{*}{$\begin{array}{l}\text { Invertendo a relação de causalidade tradicionalmente investigada na literatura, pode-se } \\
\text { especular que um desempenho melhor, por meio da avaliação do mercado ou dos retor- } \\
\text { nos passados, pode causar impacto na estrutura de propriedade. Como exemplo, uma } \\
\text { empresa com alto Q de Tobin poderia aproveitar a boa valorização dos seus papéis para } \\
\text { lançar novas ações no mercado, desta forma reduzindo a concentração da propriedade } \\
\text { (DEMSETZ, LEHN, 1985; HIMMELBERG e outros, 1999) }\end{array}$} & LOAT \\
\hline & & LOPAT \\
\hline Indústria & $\begin{array}{l}0 \text { setor de atividade da companhia pode ter influência sobre a concentração da pro- } \\
\text { priedade. Setores mais regulamentados podem ter menor concentração da proprieda- } \\
\text { de, por exemplo }\end{array}$ & IND \\
\hline $\begin{array}{l}\text { Tipo do Acionista } \\
\text { Controlador }\end{array}$ & $\begin{array}{l}0 \text { tipo de acionista controlador (privado nacional, estrangeiro, estatal, entre outros) } \\
\text { pode ter influência sobre a concentração da propriedade. Uma empresa estatal pode, } \\
\text { por exemplo, ter por lei uma concentração mínima da propriedade }\end{array}$ & TIPO \\
\hline
\end{tabular}

seja função de certos atributos corporativos e setoriais, como representado abaixo:

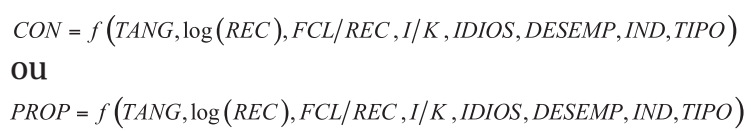

sendo que CON e PROP representam a concentração do direito de controle e do direito de propriedade (direito sobre o fluxo de caixa), respectivamente. Estimaram-se especificamente modelos lineares com os determinantes potenciais relacionados acima, acrescentando-sevariáveis de controle. A descrição de todas as variáveis está disponível no Quadro 2.

Uma das especificações formuladas, cujos parâmetros foram estimados pelo método de Mínimos Quadrados Ordinários, é mostrada na Equação 1 abaixo:

$$
\begin{aligned}
& C O N_{i t}=\alpha+\beta_{1} T A N G_{i t}+\beta_{2} \log (R E C)_{i t}+\beta_{3}(F C L / R E C)_{i t}+\beta_{4}(I / K)_{i t}+ \\
& +\beta_{5} I D I O S_{i t}+\beta_{6} D_{E S E M P_{i t}}+\beta_{7} P A Y O U T_{i t}+\sum_{j=1}^{17} \delta_{j} I N D_{j i}+\sum_{l=1}^{5} \gamma_{l} T I P O_{l i}+ \\
& +\sum_{k=1}^{4} \psi_{k} A N O_{k t}+\varepsilon_{i t}
\end{aligned}
$$


em que que i e t representam a empresa e 0 ano, respectivamente, e $\varepsilon_{\text {it }}$ representa o termo de erro aleatório da i-ésima empresa no t-ésimo ano. 0 direito de controle (CON) é utilizado como variável dependente e pode ser substituído pela variável correspondente ao direito de propriedade (PROP). Foram construídas variáveis binárias para cada ano da amostra $\left(\mathrm{AN}_{1}, \ldots, \mathrm{ANO}_{5}\right)$ com o intuito de isolar quaisquer efeitos macroeconômicos que afetaram o conjunto das empresas no período do estudo. Também como variável de controle utilizou-se o índice de payout das empresas (PAYOUT), tradicionalmente modelado como variável dependente nos estudos que relacionam medidas de desempenho à estrutura de propriedade. 0 model o linear mostra, ainda, que o setor de atividade das empresas (IND) e o tipo do acionista controlador (TIPO) são incluídos como conjuntos de variáveis binárias. Em al gumas especificações acrescentaram-se à Equação 1 termos quadráticos de alguns dos determinantes potenciais - por exemplo, o porte da empresa ao quadrado - como forma de capturar relações eventualmente não lineares no relacionamento entre as variáveis.

A validade das inferências depende da qualidade estatística dos modelos postulados, a qual foi avaliada por sua aderência aos pressupostos de um modelo de regressão linear. Dentre outros, foram empregados o teste de heterocedasticidade de Breusch e Pagan (1979) e o teste de normal idade e heterocedasticidade de Cameron e Trivedi (1990) nas análises de diagnóstico.

Todavia, a modelagem utilizando a Equação 1 e suas variantes apresenta possível deficiência por desconsiderar características não observáveis das empresas que podem prejudicar a correta identificação do relacionamento entre a concentração do direito de controle e do direito de propriedade e seus possíveis determinantes. Se algumas destas variáveis omitidas influenciarem a concentração do direito de controle ou de propriedade e estiverem correlacionadas com os regressores incluídos no modelo, os coeficientes estimados pela Equação 1 serão inconsistentes, refletindo um relacionamento espúrio entre as variáveis de interesse. Portanto, é conveniente trabalhar com a seguinte formulação geral:

$$
\begin{aligned}
& \operatorname{CON}_{i t}=\alpha+\beta_{1} T_{A N G_{i t}}+\beta_{2} \log (\text { REC })_{i t}+\beta_{3}(F C L / R E C)_{i t}+\beta_{4}(I / K)_{i t}+ \\
& +\beta_{5} I D I O S_{i t}+\beta_{6} D_{E S E M P_{i t}}+\beta_{7} \text { PAYOUT }_{i t}+\sum_{j=1}^{17} \delta_{j} I N D_{j i}+\sum_{l=1}^{5} \gamma_{l} T I P O_{l i}+ \\
& +\sum_{k=1}^{4} \psi_{k} A N O_{k t}+u_{i}+\eta_{i t}
\end{aligned}
$$

em que $i$ e t representam a empresa e 0 ano, respectivamente, $u_{i}$ é o efeito específico não observável da i-ésima empresa e $\eta_{i t}$ representa o termo de erro da i-ésima empresa no t-ésimo ano. N este caso, $\alpha$ pode ser interpretado como o efeito específico médio do conjunto das compa-

Quadro 2 - Resumo das variáveis de pesquisa

\begin{tabular}{|l|l|l|}
\hline \multicolumn{1}{|c|}{ SIGLA } & \multicolumn{1}{|c|}{ NOME } & \multicolumn{1}{c}{ DESCRIÇÃO } \\
\hline CON & Direito de controle & $\begin{array}{l}\text { Percentual de ações ordinárias em posse do(s) } \\
\text { acionista(s) controlador(es) }\end{array}$ \\
\hline PROP & Direito de propriedade & $\begin{array}{l}\text { Percentual do total de ações em posse do(s) } \\
\text { acionista(s) controlador(es) }\end{array}$ \\
\hline Q & Q de Tobin & Q $=\frac{\text { VMAO +VMAP + DIVT }}{\text { AT }}$ \\
\hline LOPAT & Rentabilidade utilizando o lucro operacional próprio & Lucro operacional próprio sobre ativo total \\
\hline LOAT & Rentabilidade utilizando o lucro operacional & Lucro operacional sobre ativo total \\
\hline IOg(REC) & Tamanho da empresa & Logaritmo do faturamento operacional líquido \\
\hline TANG & Natureza da operação & Ativo imobilizado bruto / Receita \\
\hline FCL / REC & Nível do Fluxo de Caixa Livre & Fluxo de Caixa Livre / Receita \\
\hline I/ K & Taxa de investimento da empresa & Investimentos / Ativo imobilizado \\
\hline IDIOS & Risco idiossincrático da empresa & Variância dos resíduos da regressão do CAPM \\
\hline PAYOUT & Índice de payout & Índice de payout da ação \\
\hline IND & Setor de atuação da empresa & Variáveis binárias "Indústria" \\
\hline TIPO & Tipo do acionista controlador & Variáveis binárias "Tipo do controlador" \\
\hline
\end{tabular}


nhias. 0 componente $u_{i}$ captura quaisquer características intrínsecas das empresas que não variam com o tempo e que podem influenciar a concentração do direito de controle e do direito de propriedade.

Para estimar os parâmetros da Equação 2 e suas variantes, incluindo as especificações com termos quadráticos de al guns dos regressores, foram utilizados os procedimentos deEfeitos Aleatórios (EA) ede Efeitos Fixos (EF). Quando se utilizou o estimador EF, os possíveis determinantes ficaram restritos àqueles que apresentam variação no tempo, descartando-se as variáveis IND (setor de atuação) e TIPO (tipo do acionista controlador), as quais seriam perfeitamente colineares com $u_{i}$. Em comparação com a Equação 1, a formulação acima equivale a considerar $\varepsilon_{i t}=u_{i}+\eta_{i t^{*}}$ Para produzirmos estimativas consistentes utilizando o estimador $E F$, é necessário que $\eta_{\text {it }}$ não esteja correlacionado com os regressores, sendo esta a hipótese de identificação do modelo. A consistência do estimador EA, por sua vez, depende da suposição mais restritiva de que ambos, $\eta_{\mathrm{it}}$ e $\mathrm{u}_{\mathrm{i}}$, não estejam correlacionados com os regressores.

Os argumentos apresentados anteriormente no Quadro 1 sugerem que as regressões produzi rão coeficientes estatisticamente significantes com os seguintes sinais:

- $\beta_{3^{\prime}}, \beta_{4}>0$;

- $\beta_{1}, \beta_{5}<0$;

- O sentido da associação entre o desempenho corporativo e a estrutura de propriedade, assim como entre a estrutura de propriedade e o tamanho da empresa, é incerto de antemão. Assim, não há sinal esperado para $\beta_{6}$ ou para $\beta_{2}$.

Por outro lado, é possível queas considerações teóricas referidas neste trabalho não exerçam influência de primeira ordem na determinação da estrutura de propriedade das empresas. N estecaso, CON ePROP comportar-se-ão como variáveis aproximadamente exógenas, suposição comum efreqüentemente implícita - a diversos trabalhos anteriores. Sob esta hipótese, espera-se que os coeficientes estimados não sejam estatisticamente significantes.

\section{Definição operacional das variáveis}

As definições operacionais das variáveis utilizadas na pesquisa são apresentadas a seguir. Sua descrição resumida consta no Quadro 2.

Estrutura de propriedade e controle

0 direito de controle ( $C O N$ ) e o direito sobre o fluxo de caixa (PROP) são utilizados alternativamente como variável dependente:
- direito de controle (CON) - corresponde ao direito de voto do acionista controlador. É o percentual de ações ordinárias em posse do(s) acionista(s) controlador(es);

- direito sobre o fluxo de caixa (PROP) - corresponde ao direito de propriedade do acionista controlador. É o percentual do total de ações em posse do(s) acionista(s) controlador(es) (participação no capital total da companhia).

Os dados foram coletados por meio do sistema DIVEXT Divulgação Externa da CVM, entendendo-se como acionista controlador aquele identificado pela própria empresa em seu Informativo Anual (IAN). Para a correta identificação do percentual de votos em posse dos controladores, foram analisadas também as estruturas piramidais de propriedade, identificando-se os proprietários em comum entre vários acionistas e não somente o controle direto. No caso de estruturas familiares, computou-se a soma do bloco controlador, levando-se em consideração a posse de ações por parentes com mesmo sobrenome. Para o caso de haver um acordo de acionistas, foi considerada a porcentagem de controle total do bloco do acordo.

\section{Desempenho corporativo}

Existem várias definições possíveis para este conceito. No estudo são utilizadas duas formas de medida de desempenho: as relacionadas ao valor de mercado da empresa eas relacionadas a sua rentabilidade histórica. Como métrica relacionada ao valor de mercado, utilizou-se o $Q$ de Tobin (Q). Como métricas relacionadas à rentabilidade, utilizouse o retorno sobre 0 ativo com base no lucro operacional ( LOAT) e no lucro operacional próprio (LOPAT).

- Q de Tobin (Q): estimado pela aproximação proposta por Chung e Pruitt (1994) e definido operacionalmente como:

$Q$ de Tobin $\cong \frac{\text { VMAO +VMAP +DIVT }}{A T}$

Onde: VMAO - valor de mercado das ações ordinárias; VMAP - valor de mercado das ações preferenciais; DIVT valor contábil da dívida, definido como o passivo circulante menos 0 ativo circulante acrescido do exigível a longo prazo mais os estoques; AT - ativo total da companhia. Os dados contábeis das empresas são referentes ao respectivo exercício e a cotação corresponde ao preço médio do último dia de negociação de cada ano. Em alguns casos, devido à ausência de informação, a cotação da ação ordinária foi aproximada pela cotação da ação preferencial.

- LOPAT: é o lucro operacional próprio sobre o ativo total. 
O lucro operacional próprio éo lucro operacional antes das receitas e despesas financeiras.

- LOAT : é o lucro operacional sobre o ativo total.

Para o cálculo dos dois indicadores, foram considerados os valores nominais relativos ao final de cada exercício.

\section{Porte da empresa}

O porte da empresa $(\log (\mathrm{REC}))$ é definido como o logaritmo natural de seu faturamento operacional líquido e medido em milhares de reais, em valores nominais, ao fim de cada exercício.

\section{Setor de atuação}

O setor de atuação pode exercer influência sobre o nível de governança corporativa, a concentração da estrutura de propriedade e o desempenho. Utilizaram-se variáveis binárias (IND) para representar os diferentes setores. Estas variáveis atribuem valor 1 para as empresas pertencentes a um setor específico e 0 para as pertencentes aos demais setores. Adotou-se o critério de classificação do banco de dados Economática ${ }^{\circledR}$, que fornece a relação das empresas e dos seus respectivos setores. É uma classificação ampla, dividindo as empresas em 18 categorias:

Setores Economática ${ }^{\oplus}$ : Agro e Pesca; Alimentos e Bebidas; Comércio; Construção; Eletroeletrônicos; Energia Elétrica; Máquinas Industriais; Mineração; Minerais não M etálicos; Outros; Papel e Celulose; Petróleo e Gás; Química; Siderurgia e Metalurgia; Telecomunicações; Têxtil; Transportes, Serviços; Veículos e Peças.

As variáveis binárias setoriais foram codificadas na ordem acima, ou seja, IND 1 =Agro e Pesca, IND 2 =Alimentos e Bebidas e assim sucessivamente.

\section{Tipo de acionista controlador}

Além da variável de concentração do direito de controle, também foi considerado o tipo de acionista controlador, por meio de um conjunto de variáveis binárias:

- propriedade privada estrangeira: quando uma multinacional ou grupo de investidores de origem estrangeira detém o controle da empresa ( $\mathrm{TIPO}_{1}$ );

- propriedade privada nacional: quando um grupo de investidores de origem nacional controla a empresa, não sendo os investidores fundadores ou herdeiros da empresa $\left(\mathrm{TIPO}_{2}\right)$;

- propriedade familiar: quando uma família ou um único investidor detém o controle, incluindo-seneste caso os controles exercidos por fundações ou por holdings que representam os fundadores ou herdeiros da empresa $\left(\mathrm{TIPO}_{3}\right)^{2}$;

- propriedade por bancos e outras instituições financeiras: quando um banco e/ou instituição financeira detém o controle da empresa $\left(\mathrm{TIPO}_{4}\right)$;

- propriedade por fundos de pensão: quando o controleé exercido de forma compartilhada por fundos de pensão $\left(\mathrm{TIPO}_{5}\right)$;

- propriedade estatal: quando o controle é exercido pelo Estado (União, Estados ou Municípios) $\left(\mathrm{TIPO}_{6}\right)$.

\section{Natureza da operação}

É uma aproximação para o nível de tangibilidade das operações da empresa, dada pela composição dos seus ativos. É definida como 0 ativo imobilizado bruto sobre a receita operacional líquida da empresa (TANG), ambos medidos em valores contábeis, em reais nominais, ao final de cada exercício.

\section{Payout}

É dado pelo índice de payout anual da ação calculado pelo sistema Economática ${ }^{\circledR}$. É definido como dividendos pagos por ação sobre o lucro líquido por ação, ambos medidos em reais nominais ao final de cada exercício.

\section{Nível do fluxo de caixa livre}

0 nível de fluxo de caixa livre possui relação com o montante de gastos definidos pelo livre-arbítrio do gestor/ empreendedor e com os benefícios privados potenciais do controle. Desta forma, o nível do fluxo de caixa livre pode ter relação com a concentração da propriedade desejada pelo insider. Como aproximação para esta variável (FCL / REC), utilizou-se uma versão contábil do fluxo de caixa livre da empresa sobre sua receita operacional líquida, ambas medidas em reais nominais, ao final de cada exercício. 0 fluxo de caixa livre foi calculado pela seguinte equação:

$$
F C L=L L-A u m C G L+\text { DepAmort }-I n v
$$

em que FCL - Fluxo de Caixa Livre da empresa; LL Lucro Líquido; AumCGL - Investimento em capital de giro líquido; D epAmort - Depreciação e Amortização; Inv - Investimentos em ativo fixo.

\section{Taxa de investimento da empresa}

A taxa de investimento da empresa (I / K) foi definida como o investimento em ativo fixo da empresa (I) sobre seu ativo imobilizado bruto (K), ambos medidos em valores contábeis, em reais nominais, ao final de cada exercício. 
Risco idiossincrático da empresa

0 risco idiossincrático (IDIOS) de um ativo pode ser calculado por meio da seguinte equação, com base na teoria do CAPM (Capital Asset Pricing M odel):

$$
\operatorname{var}\left(R_{A}\right)=\beta_{A}^{2} \operatorname{var}\left(R_{M}\right)+e_{s_{A}}^{2}
$$

em que $\operatorname{var}\left(R_{A}\right)$ - Variância da taxa de retorno de um ativo $A$ qualquer (risco total); $\operatorname{var}\left(R_{M}\right)$ - Variância da taxa de retorno da carteira de mercado; $\beta_{\mathrm{A}}$ - beta do ativo $\mathrm{A}$ (risco sistemático); $e_{S_{A}}-$ Risco idiossincrático ou risco próprio do ativo $A$.

Reordenando os termos da equação, obtém-se a fórmula aplicada para o cálculo do risco idiossincrático: $e_{S_{A}}=\sqrt{\operatorname{var}\left(R_{A}\right)-\beta_{A}^{2} \operatorname{var}\left(R_{M}\right)}$. Foram utilizados dados de volatilidade anual dos retornos da ação de cada empresa, 0 beta da ação em relação ao I bovespa para um período de doze meses anteriores e a volatilidade dos retornos do I bovespa (adotado como carteira de mercado).

\section{População, amostragem e coleta de dados}

A amostra do estudo é composta por todas as companhias abertas não financeiras negociadas na Bolsa de Valores de São Paulo (Bovespa), que apresentaram liquidez significativa nos anos de 1998 a 2002. Consideraram-se como empresas com liquidez significativa aquelas que, de acordo com o índice Economática ${ }^{\circledR}$, apresentaram liquidez anual de suas ações maior do que $0,001 \%$ do índice da empresa mais líquida em $50 \%$ ou mais dos anos em que a ação foi negociada, incluindo necessariamente 0 ano de
2002. A escolha desta faixa de corte para a definição da amostra, em vez da coleta de dados de todas as companhias abertas, se deve ao fato de que as ações de empresas com liquidez muito baixa possuem probabilidade menor de terem suas cotações adequadas ao valor de mercado, sendo a cotação das ações necessária para o cálculo do $Q$ de Tobin. Algumas empresas não apresentaram dados suficientes para a construção de diversas variáveis, reduzindo o tamanho da amostra a um total de 161 empresas e 776 observações. Utilizaram-se dados secundários coletados junto aos sistemas de informações Economática ${ }^{\circledR} \mathrm{e}$ Divulgação Externa ITR/DFP/IAN (DIVEXT) da Comissão de Valores Mobiliários.

\section{RESULTADOS DA PESQUISA}

Os dados relativos às variáveis de estrutura de controle e desempenho referentes à amostra anal isada são resumidos na Tabela 1, com suas respectivas estatísticas descritivas. Observa-se na tabela que a concentração média de votos dos acionistas controladores ( $\mathrm{CON}$ ) nas companhias abertas é alta, apresentando média de 73,92\%. Ademais, a concentração média aumentou durante o período da amostra, de 72,73\% em 1998 para 75,39\% em 2002, com elevações em todos os anos. Todavia, testes convencionais de diferenças de média revelaram que as diferenças entre os anos não são estatisticamente significantes nos níveis de 5 e 10\%. Comportamento análogo é observado para a concentração da propriedade (PROP), cujo valor

Tabela 1 - Estatísticas descritivas das variáveis de concentração e desempenho

\begin{tabular}{|c|c|c|c|c|c|c|c|}
\hline & & $\mathrm{CON}$ & PROP & Q & LOPAT & LOAT & $\begin{array}{l}\text { EMPRESAS } \\
\text { (AMOSTRA) }\end{array}$ \\
\hline \multirow{5}{*}{ Média } & 1998 & $72,73 \%$ & $48,39 \%$ & 0,45 & $5,72 \%$ & $6,40 \%$ & 161 \\
\hline & 1999 & $72,79 \%$ & $49,01 \%$ & 0,77 & $6,80 \%$ & $-2,61 \%$ & 161 \\
\hline & 2000 & $73,55 \%$ & $50,36 \%$ & 0,68 & $7,83 \%$ & $2,50 \%$ & 161 \\
\hline & 2001 & $74,98 \%$ & $52,15 \%$ & 0,68 & $8,79 \%$ & $2,39 \%$ & 161 \\
\hline & 2002 & $75,39 \%$ & $53,54 \%$ & 0,71 & $8,68 \%$ & $-0,85 \%$ & 161 \\
\hline \multirow{5}{*}{ Amostra total } & Média & $73,92 \%$ & $50,74 \%$ & 0,66 & $7,60 \%$ & $1,53 \%$ & \multirow{5}{*}{161} \\
\hline & Desvio & $20,22 \%$ & $23,80 \%$ & 0,59 & $7,82 \%$ & $14,55 \%$ & \\
\hline & $1^{\circ}$ Quartil & $57,29 \%$ & $31,52 \%$ & 0,39 & $3,48 \%$ & $-1,60 \%$ & \\
\hline & Mediana & $75,95 \%$ & $49,10 \%$ & 0,59 & $7,90 \%$ & $3,03 \%$ & \\
\hline & $3^{\circ}$ Quartil & $91,60 \%$ & $68,99 \%$ & 0,81 & $11,63 \%$ & $7,33 \%$ & \\
\hline
\end{tabular}


médio na amostra é de $50,74 \%$. A concentração média da propriedade também cresceu em todos os anos, passando de 48,39\% em 1998 para 53,54\% em 2002. A diferença entre o valor médio de 1998 e o de 2002 desta variável é estatisticamente significante no nível de 10\% (as demais diferenças entre os anos são não significantes). Ressal ta-se, ainda, a expressiva disparidade entre a concentração dos direitos de controle e de propriedade, cujo valor médio é de $23,18 \%$ (73,92\% - 50,74\%) para o período da amostra. A referida disparidade reduziu-se ao longo dos anos pesquisados, passando de 24,34\% em 1998 para 21,85\% em 2002, porém estas variações temporais não se revelam estatisticamente significantes nos níveis usuais.

Com relação às variáveis de desempenho, constata-se, com base no $\mathrm{Q}$ de Tobin médio menor do que 1 durante todo o período, que as empresas da amostra têm papéis relativamente pouco valorizados, o que sugere que, em média, elas têm investido em projetos que não maximizam valor para seus acionistas, ou não têm distribuído adequadamente os proventos para seus minoritários, ao menos na percepção do mercado. A análise da variação temporal revela um aumento estatisticamente significante no nível de $1 \%$ do Q médio entre 1998 e 1999. As variações subseqüentes da variável não se mostram significantes nos níveis usuais. Por sua vez, o retorno sobre 0 ativo baseado no lucro operacional próprio das empresas mostra al guma tendência de crescimento ao longo do período, confirmada pela significância no nível de 1\% das diferenças entre as médias de 1998 e 2001 e 1998 e 2002. A medida de rentabilidade baseada no lucro operacional, por outro lado, apresenta um comportamento temporal errático, com variações bastante significativas (e estatisticamente significantes) entre al guns dos anos estudados, possivel mente refletindo as mudanças bruscas de custo do financiamento ocorridas ao longo do período.
Os valores médios da variável Tipo do Acionista Controlador são apresentados na Tabela 2. A tabela mostra que quase metade $(47,04 \%)$ do controle das empresas da amostra está nas mãos de famílias ou controladores individuais. Esta proporção caiu em todos os anos do estudo, passando de 48,65\% em 1998 para $45,96 \%$ em 2002. Todas estas variações não são estatisticamente significantes nos níveis convencionais, entretanto. Observase ainda a pouca presença de bancos ou outras instituições financeiras no controle das empresas, representando apenas $0,64 \%$ da amostra, lembrando que isso não implica ausência de bancos ou instituições financeiras nas participações, mas sim no papel de controladores. Existe ainda uma proporção significativa de controladores estrangeiros, constituindo $23,3 \%$ da amostra. A participação do controle estrangeiro aumentou em todos os anos, passando de 21,62\% em 1998 para 24,22\% em 2002 , embora, novamente, as variações entre os anos não sejam estatisticamente significantes. O bserva-se uma proporção média de $16,88 \%$ de controladores nacionais (não familiares) e uma proporção de 5,15\% de empresas controladas por fundos de pensão.

Os principais resultados da pesquisa são apresentados nas Tabelas 3 e 4. Inicialmente, construiu-se uma matriz de correlações a fim de avaliar possíveis problemas de multicolinearidade. A matriz revelou correlações baixas entre as variáveis.

Os primeiros procedimentos de regressão utilizaram o método dos Mínimos Quadrados O rdinários (M Q O) com as variáveis alternativas de desempenho e diversas especificações plausíveis. Na Tabela 3 reportam-se as regressões utilizando a concentração do direito de controle (CON) como variável dependente e na Tabela 4 aparecem as regressões nas quais a variável dependente é a concentração do direito de propriedade (PROP).

Tabela 2 - Identidade do acionista controlador (TIPO)

\begin{tabular}{|l|c|c|c|c|c|c|c|}
\hline & $\begin{array}{c}\text { PRIVADO } \\
\text { ES TRANGEIRO }\end{array}$ & $\begin{array}{c}\text { PRIVADO } \\
\text { NACIONAL }\end{array}$ & FAMILIAR & $\begin{array}{c}\text { INSTTIUIÇOES } \\
\text { FINANCEIRAS }\end{array}$ & $\begin{array}{c}\text { FUNDOS DE } \\
\text { PENSÃO }\end{array}$ & ESTATAL & $\begin{array}{c}\text { AMOSTRA } \\
\text { (EMPRESAS) }\end{array}$ \\
\hline 1998 & $21,62 \%$ & $16,89 \%$ & $48,65 \%$ & $0,68 \%$ & $5,41 \%$ & $6,76 \%$ & 161 \\
\hline 1999 & $23,03 \%$ & $16,45 \%$ & $47,37 \%$ & $0,66 \%$ & $5,26 \%$ & $7,24 \%$ & 161 \\
\hline 2000 & $23,72 \%$ & $16,67 \%$ & $46,79 \%$ & $0,64 \%$ & $5,13 \%$ & $7,05 \%$ & 161 \\
\hline 2001 & $23,90 \%$ & $16,98 \%$ & $46,54 \%$ & $0,63 \%$ & $5,03 \%$ & $6,92 \%$ & 161 \\
\hline 2002 & $24,22 \%$ & $17,39 \%$ & $45,96 \%$ & $0,62 \%$ & $4,97 \%$ & $6,83 \%$ & 161 \\
\hline Média & $23,32 \%$ & $16,88 \%$ & $47,04 \%$ & $0,64 \%$ & $5,15 \%$ & $6,96 \%$ & 161 \\
\hline
\end{tabular}


Tabela 3 - Possíveis determinantes da concentração do direito de controle (CON)

\begin{tabular}{|c|c|c|c|c|c|c|c|c|c|}
\hline & $\begin{array}{l}\text { MQO } \\
(1)\end{array}$ & $\begin{array}{l}\text { MQO } \\
(2)\end{array}$ & $\begin{array}{l}\text { MQO } \\
(3)\end{array}$ & $\begin{array}{l}\text { EA } \\
(4)\end{array}$ & $\begin{array}{l}\text { EA } \\
(5)\end{array}$ & $\begin{array}{l}\text { EA } \\
(6)\end{array}$ & $\begin{array}{l}\mathrm{EF} \\
(7)\end{array}$ & $\begin{array}{l}\text { EF } \\
(8)\end{array}$ & $\begin{array}{l}\text { EF } \\
(9)\end{array}$ \\
\hline TANG & $\begin{array}{l}0,004 \\
(0,70)\end{array}$ & $\begin{array}{l}0,003 \\
(0,54)\end{array}$ & $\begin{array}{l}0,002 \\
(0,38)\end{array}$ & $\begin{array}{l}-0,003 \\
(-0,60)\end{array}$ & $\begin{array}{l}-0,001 \\
(-0,10)\end{array}$ & $\begin{array}{l}-0,001 \\
(-0,20)\end{array}$ & $\begin{array}{l}-0,006 \\
(-0,67)\end{array}$ & $\begin{array}{l}-0,005 \\
(-0,90)\end{array}$ & $\begin{array}{l}-0,005 \\
(-1,01)\end{array}$ \\
\hline $\log (\mathrm{REC})$ & $\begin{array}{l}-0,027 \\
(-1,62)\end{array}$ & $\begin{array}{l}-0,026 \\
(-1,55)\end{array}$ & $\begin{array}{l}-0,021 \\
(-1,19)\end{array}$ & $\begin{array}{l}-0,012 \\
(-0,72)\end{array}$ & $\begin{array}{l}-0,018 \\
(-0,97)\end{array}$ & $\begin{array}{l}-0,012 \\
(-0,66)\end{array}$ & $\begin{array}{l}-0,007 \\
(-0,27)\end{array}$ & $\begin{array}{l}-0,003 \\
(-0,14)\end{array}$ & $\begin{array}{l}-0,005 \\
(-0,23)\end{array}$ \\
\hline $\mathrm{FCL} / \mathrm{REC}$ & $\begin{array}{l}0,013^{* *} \\
(2,47)\end{array}$ & $\begin{array}{l}0,013^{* *} \\
(2,14)\end{array}$ & $\begin{array}{l}0,013^{* *} \\
(2,23)\end{array}$ & $\begin{array}{l}0,000 \\
(-0,03)\end{array}$ & $\begin{array}{l}0,000 \\
(-0,01)\end{array}$ & $\begin{array}{l}0,000 \\
(-0,02)\end{array}$ & $\begin{array}{l}-0,001 \\
(-0,39)\end{array}$ & $\begin{array}{l}-0,001 \\
(-1,00)\end{array}$ & $\begin{array}{l}-0,001 \\
(-0,98)\end{array}$ \\
\hline I/K & $\begin{array}{l}0,017^{*} \\
(1,87)\end{array}$ & $\begin{array}{l}0,019 * * * \\
(2,58)\end{array}$ & $\begin{array}{l}0,018^{* *} \\
(2,23)\end{array}$ & $\begin{array}{l}0,006 \\
(1,22)\end{array}$ & $\begin{array}{l}0,006 \\
(1,00)\end{array}$ & $\begin{array}{l}0,005 \\
(0,85)\end{array}$ & $\begin{array}{l}0,006 \\
(0,96)\end{array}$ & $\begin{array}{l}0,006 \\
(1,24)\end{array}$ & $\begin{array}{l}0,006 \\
(0,97)\end{array}$ \\
\hline IDIOS & $\begin{array}{l}0,020 \\
(0,42)\end{array}$ & $\begin{array}{l}0,023 \\
(0,48)\end{array}$ & $\begin{array}{l}0,015 \\
(0,31)\end{array}$ & $\begin{array}{l}0,001 \\
(0,04)\end{array}$ & $\begin{array}{l}0,005 \\
(0,23)\end{array}$ & $\begin{array}{l}0,001 \\
(0,06)\end{array}$ & $\begin{array}{l}-0,001 \\
(-0,06)\end{array}$ & $\begin{array}{l}-0,001 \\
(-0,04)\end{array}$ & $\begin{array}{l}-0,005 \\
(-0,24)\end{array}$ \\
\hline Q & $\begin{array}{l}0,037^{* * *} \\
(2,98)\end{array}$ & & & $\begin{array}{l}-0,013 \\
(-0,72)\end{array}$ & & & $\begin{array}{l}-0,019 \\
(-0,94)\end{array}$ & & \\
\hline LOAT & & $\begin{array}{l}0,024 \\
(0,54)\end{array}$ & & & $\begin{array}{l}0,015 \\
(0,54)\end{array}$ & & & $\begin{array}{l}0,015 \\
(0,59)\end{array}$ & \\
\hline LOPAT & & & $\begin{array}{l}-0,099 \\
(-0,91)\end{array}$ & & & $\begin{array}{l}-0,087 \\
(-1,20)\end{array}$ & & & $\begin{array}{l}-0,096 \\
(-1,21)\end{array}$ \\
\hline TPO 1 & $\begin{array}{l}-0,029 \\
(-0,77)\end{array}$ & $\begin{array}{l}-0,031 \\
(-0,85)\end{array}$ & $\begin{array}{l}-0,038 \\
(-1,02)\end{array}$ & $\begin{array}{l}-0,083 \\
(-1,04)\end{array}$ & $\begin{array}{l}-0,082 \\
(-1,01)\end{array}$ & $\begin{array}{l}-0,089 \\
(-1,14)\end{array}$ & & & \\
\hline TIPO 2 & $\begin{array}{l}-0,134 * * * \\
(-3,51)\end{array}$ & $\begin{array}{l}-0,134 * * * \\
(-3,56)\end{array}$ & $\begin{array}{l}-0,145^{* * *} \\
(-3,69)\end{array}$ & $\begin{array}{l}-0,136 \\
(-1,63)\end{array}$ & $\begin{array}{l}-0,135 \\
(-1,58)\end{array}$ & $\begin{array}{l}-0,144 * \\
(-1,76)\end{array}$ & & & \\
\hline TPO 3 & $\begin{array}{l}-0,108 * * * \\
(-3,22)\end{array}$ & $\begin{array}{l}-0,113 * * * \\
(-3,41)\end{array}$ & $\begin{array}{l}-0,121 * * * \\
(-3,61)\end{array}$ & $\begin{array}{l}-0,130 * \\
(-1,70)\end{array}$ & $\begin{array}{l}-0,127 \\
(-1,63)\end{array}$ & $\begin{array}{l}-0,134 * \\
(-1,79)\end{array}$ & & & \\
\hline TPO 5 & $\begin{array}{l}-0,135^{* *} \\
(-2,46)\end{array}$ & $\begin{array}{l}-0,139 * * * \\
(-2,59)\end{array}$ & $\begin{array}{l}-0,144 * * * \\
(-2,68)\end{array}$ & $\begin{array}{l}-0,172^{*} \\
(-1,73)\end{array}$ & $\begin{array}{l}-0,170^{*} \\
(-1,68)\end{array}$ & $\begin{array}{l}-0,176^{*} \\
(-1,79)\end{array}$ & & & \\
\hline TPO 6 & $\begin{array}{l}-0,068 \\
(-1,27)\end{array}$ & $\begin{array}{l}-0,075 \\
(-1,42)\end{array}$ & $\begin{array}{l}-0,084 \\
(-1,57)\end{array}$ & $\begin{array}{l}-0,149 \\
(-1,40)\end{array}$ & $\begin{array}{l}-0,147 \\
(-1,36)\end{array}$ & $\begin{array}{l}-0,157 \\
(-1,51)\end{array}$ & & & \\
\hline PAYOUT & $\begin{array}{l}-0,0003 \\
(-1,30)\end{array}$ & $\begin{array}{l}-0,0003 \\
(-1,30)\end{array}$ & $\begin{array}{l}-0,0003 \\
(-1,59)\end{array}$ & $\begin{array}{l}-0,0000 \\
(0,04)\end{array}$ & $\begin{array}{l}-0,0000 \\
(0,17)\end{array}$ & $\begin{array}{l}-0,0000 \\
(0,10)\end{array}$ & $\begin{array}{l}0,0000 \\
(0,21)\end{array}$ & $\begin{array}{l}0,0000 \\
(0,53)\end{array}$ & $\begin{array}{l}0,0000 \\
(0,07)\end{array}$ \\
\hline IND 3 & $\begin{array}{l}-0,253^{* * *} \\
(-4,34)\end{array}$ & $\begin{array}{l}-0,255^{* * *} \\
(-4,29)\end{array}$ & $\begin{array}{l}-0,255^{* * *} \\
(-4,31)\end{array}$ & $\begin{array}{l}-0,253^{* *} \\
(-2,19)\end{array}$ & $\begin{array}{l}-0,274 * * * \\
(-3,24)\end{array}$ & $\begin{array}{l}-0,277 * * * \\
(-3,40)\end{array}$ & & & \\
\hline IND 4 & $\begin{array}{l}-0,153^{* * *} \\
(-2,66)\end{array}$ & $\begin{array}{l}-0,163 * * * \\
(-2,78)\end{array}$ & $\begin{array}{l}-0,161^{* * *} \\
(-2,76)\end{array}$ & $\begin{array}{l}-0,081 \\
(-0,41)\end{array}$ & $\begin{array}{l}-0,098 \\
(-0,56)\end{array}$ & $\begin{array}{l}-0,097 \\
(-0,57)\end{array}$ & & & \\
\hline IND 5 & $\begin{array}{l}0,110 * * * \\
(2,68)\end{array}$ & $\begin{array}{l}0,105^{* *} \\
(2,52)\end{array}$ & $\begin{array}{l}0,101^{* *} \\
(2,44)\end{array}$ & $\begin{array}{l}0,113 \\
(1,09)\end{array}$ & $\begin{array}{l}0,097 \\
(1,50)\end{array}$ & $\begin{array}{l}0,092 \\
(1,53)\end{array}$ & & & \\
\hline IND 11 & $\begin{array}{l}0,130 * * * \\
(2,98)\end{array}$ & $\begin{array}{l}0,133 * * * \\
(3,02)\end{array}$ & $\begin{array}{l}0,134 * * * \\
(3,04)\end{array}$ & $\begin{array}{l}0,141 \\
(1,25)\end{array}$ & $\begin{array}{l}0,120 \\
(1,53)\end{array}$ & $\begin{array}{l}0,117 \\
(1,57)\end{array}$ & & & \\
\hline IND 12 & $\begin{array}{l}-0,258 * * * \\
(-4,46)\end{array}$ & $\begin{array}{l}-0,253 * * * \\
(-4,29)\end{array}$ & $\begin{array}{l}-0,255^{* * *} \\
(-4,33)\end{array}$ & $\begin{array}{l}-0,229 * \\
(-1,87)\end{array}$ & $\begin{array}{l}-0,250 * * * \\
(-2,62)\end{array}$ & $\begin{array}{l}-0,256 * * * \\
(-2,85)\end{array}$ & & & \\
\hline
\end{tabular}




\begin{tabular}{|c|c|c|c|c|c|c|c|c|c|}
\hline & & & & & & & & & (conclusão) \\
\hline IND 15 & $\begin{array}{l}-0,090 * * \\
(-2,15)\end{array}$ & $\begin{array}{l}-0,078^{*} \\
(-1,88)\end{array}$ & $\begin{array}{l}-0,081^{*} \\
(-1,94)\end{array}$ & $\begin{array}{l}-0,067 \\
(-0,65)\end{array}$ & $\begin{array}{l}-0,090 \\
(-1,34)\end{array}$ & $\begin{array}{l}-0,090 \\
(-1,34)\end{array}$ & & & \\
\hline Intercepto & $\begin{array}{l}0,964 * * * \\
(9,45)\end{array}$ & $\begin{array}{l}0,986^{* * *} \\
(9,53)\end{array}$ & $\begin{array}{l}0,976^{* * *} \\
(9,46)\end{array}$ & $\begin{array}{l}0,933^{* * *} \\
(6,13)\end{array}$ & $\begin{array}{l}0,942 * * * \\
(8,17)\end{array}$ & $\begin{array}{l}0,924 * * * \\
(8,38)\end{array}$ & $\begin{array}{l}0,784 * * * \\
(6,12)\end{array}$ & $\begin{array}{l}0,751 * * * \\
(6,08)\end{array}$ & $\begin{array}{l}0,716 * * * \\
(5,60)\end{array}$ \\
\hline$R^{2}$ & $24,8 \%$ & $24,1 \%$ & $24,1 \%$ & $21,52 \%$ & $22,18 \%$ & $22,21 \%$ & $0,26 \%$ & $0,03 \%$ & $0,06 \%$ \\
\hline Empresas & 152 & 152 & 152 & 152 & 152 & 152 & 152 & 152 & 152 \\
\hline
\end{tabular}

$* * *, * * \mathrm{e}^{*}$ correspondem à significância estatística nos níveis de $1 \%, 5 \%$ e $10 \%$, respectivamente.

Nota: A definição das variáveis independentes é apresentada no Quadro 2. Foram incluídas dummies de ano, omitidas da tabela por limitação de espaço. Também são omitidas as variáveis binárias setoriais (IND) cujos coeficientes não são significantes em nenhuma regressão. Os dados são relativos ao período de 1998 a 2002. Os números entre parênteses indicam a estatística t no caso dos métodos dos Mínimos Quadrados Ordinários (MQO) e de Efeitos Fixos (EF) e indicam a estatística z no caso do procedimento de Efeitos Aleatórios (EA). Os erros-padrão computados para todas as regressões são robustos a heterocedasticidade.

Os resultados das regressões por M QO apontam para uma relação positiva significante no nível de $5 \%$ ou $10 \%$ entre os regressores nível do fluxo de caixa livre (FCL / REC) e taxa de investimentos (I / K ) e as variáveis dependentes concentração do direito de controle e concentração do direito de propriedade. Estes resultados se al inham ao argumento segundo o qual uma quantidade maior de recursos disponíveis para alocação por parte do gestor ou empreendedor aumenta a concentração dos direitos de controle e de propriedade desejada por ele.

Das variáveis de desempenho, aúnica que se mostrou estatisticamente significante em todas as especificações é o Q de Tobin. Os resultados, neste caso, sugerem que a relação de causalidade entre desempenho ou valor e estrutura de propriedade pode ser invertida. Em outras palavras, assim como a concentração relativa da propriedade ou do direito de voto pode influenciar o desempenho, ela também pode ser simultaneamente influenciada por ele. No caso em questão, o Q de Tobin parece exercer um impacto positivo sobre a concentração tanto do direito de controle quanto do direito de propriedade.

Alguns dos regressores relacionados à identidade do acionista controlador apresentaram significância no nível de $1 \%$ em todas as especificações estimadas por MQO. As estimativas reportadas refletem o fato de que a empresa controlada por bancos e outras instituições financeiras $\left(\mathrm{TIPO}_{4}\right)$ revelou a mais alta concentração de direitos de voto e de direitos de propriedade. Em comparação com ela, as empresas controladas pelos demais tipos de acionista controlador possuem estrutura de propriedade substancialmente mais pulverizada, em especial aquelas de propriedade privada nacional $\left(\mathrm{TIPO}_{2}\right)$ e as estatais $\left(\mathrm{TIPO}_{6}\right)$, mesmo sem abrir mão da elevada concentração do direito de controle. As empresas de controle familiar $\left(\mathrm{TIPO}_{3}\right)$, por sua vez, revelaram-se, em média, mais pulverizadas do que as demais empresas quanto aos direitos sobre o fluxo de caixa (PROP) e menos pulverizadas do que a média geral quanto aos direitos de voto (CON), o que pode ser explicado pela emissão substancial de ações sem direito a voto. A mesma interpretação parece aplicar-se às empresas estatais. Também os coeficientes de al gumas das 18 variáveis binárias setoriais mostraram-se significantes em todas as especificações. Em particular, mesmo após o controle por outras características observáveis, as empresas pertencentes aos setores de Comércio (IND 3) e de Petróleo e Gás (IND 12) - segundo classificação da Economática ${ }^{\circledR}$ apresentaram concentração do direito sobre o fluxo de caixa e do direito de voto entre $23 \%$ e $32 \%$ inferior à concentração média, aproximadamente. Similarmente, dependendo da especificação estimada, as empresas pertencentes aos setores de Telecomunicações (IND 15), Siderurgia e M etalurgia (IND 14), Construção (IND 4) e M ineração (IND 8) apresentam concentração dos direitos de voto e/ou dos direitos de propriedade abaixo da média geral. Já as empresas pertencentes aos setores de Papel e Celulose (IND 11), Minerais Não-M etálicos (IND 9) e Eletroel etrônicos (IND 5) apresentaram valores substancialmente acima da média para CON ou PROP.

Por fim, nas regressões preliminares as empresas maiores parecem, em média, ter estrutura de propriedade mais concentrada quando se utiliza PROP como a variável dependente. Este resultado não se mantém, todavia, quando a variável dependente é a concentração do direito de controle. Ademais, encontrou-se relação positiva significante no nível de $5 \%$ entre a tangibilidade das operações (TANG) e a concentração do direito sobre o fluxo de caixa (PROP), contrariando a sugestão 
Tabela 4 - Possíveis determinantes da concentração do direito de propriedade (PROP)

\begin{tabular}{|c|c|c|c|c|c|c|c|c|c|}
\hline & $\begin{array}{l}\text { MQO } \\
(1)\end{array}$ & $\begin{array}{l}\text { MQO } \\
(2)\end{array}$ & $\begin{array}{l}M Q 0 \\
(3)\end{array}$ & $\begin{array}{l}E A \\
(4)\end{array}$ & $\begin{array}{l}\text { EA } \\
(5)\end{array}$ & $\begin{array}{l}\text { EA } \\
(6)\end{array}$ & $\begin{array}{l}\text { EF } \\
(7)\end{array}$ & $\begin{array}{l}\text { EF } \\
(8)\end{array}$ & $\begin{array}{l}\text { EF } \\
(9)\end{array}$ \\
\hline TANG & $\begin{array}{l}0,025 * * * \\
(3,67)\end{array}$ & $\begin{array}{l}0,023 * * * \\
(3,29)\end{array}$ & $\begin{array}{l}0,023 * * * \\
(3,25)\end{array}$ & $\begin{array}{l}-0,002 \\
(-0,28)\end{array}$ & $\begin{array}{l}-0,002 \\
(-0,30)\end{array}$ & $\begin{array}{l}-0,003 \\
(-0,42)\end{array}$ & $\begin{array}{l}-0,022^{* *} \\
(-2,31)\end{array}$ & $\begin{array}{l}-0,021 * * \\
(-2,27)\end{array}$ & $\begin{array}{l}-0,021^{* *} \\
(-2,27)\end{array}$ \\
\hline $\log (\mathrm{REC})$ & $\begin{array}{l}0,048 * * * \\
(2,71)\end{array}$ & $\begin{array}{l}0,052^{* * *} \\
(2,78)\end{array}$ & $\begin{array}{l}0,052^{* * *} \\
(2,63)\end{array}$ & $\begin{array}{l}0,022 \\
(1,02)\end{array}$ & $\begin{array}{l}0,019 \\
(0,88)\end{array}$ & $\begin{array}{l}0,031 \\
(1,38)\end{array}$ & $\begin{array}{l}-0,016 \\
(-0,56)\end{array}$ & $\begin{array}{l}-0,013 \\
(-0,52)\end{array}$ & $\begin{array}{l}0,004 \\
(0,14)\end{array}$ \\
\hline FCL/ REC & $\begin{array}{l}0,015^{* *} \\
(2,48)\end{array}$ & $\begin{array}{l}0,014 * * \\
(2,07)\end{array}$ & $\begin{array}{l}0,014 * * \\
(2,01)\end{array}$ & $\begin{array}{l}0,001 \\
(0,12)\end{array}$ & $\begin{array}{l}0,000 \\
(0,11)\end{array}$ & $\begin{array}{l}0,001 \\
(0,13)\end{array}$ & $\begin{array}{l}-0,003 \\
(-1,31)\end{array}$ & $\begin{array}{l}-0,003 \\
(-1,24)\end{array}$ & $\begin{array}{l}-0,002 \\
(-1,18)\end{array}$ \\
\hline I/K & $\begin{array}{l}0,021^{* *} \\
(2,05)\end{array}$ & $\begin{array}{l}0,023^{* *} \\
(2,46)\end{array}$ & $\begin{array}{l}0,024 * * \\
(2,55)\end{array}$ & $\begin{array}{l}0,008 \\
(1,24)\end{array}$ & $\begin{array}{l}0,009 \\
(1,43)\end{array}$ & $\begin{array}{l}0,007 \\
(1,03)\end{array}$ & $\begin{array}{l}0,006 \\
(1,10)\end{array}$ & $\begin{array}{l}0,008 \\
(1,46)\end{array}$ & $\begin{array}{l}0,006 \\
(0,95)\end{array}$ \\
\hline IDIOS & $\begin{array}{l}0,073 \\
(1,42)\end{array}$ & $\begin{array}{l}0,073 \\
(1,34)\end{array}$ & $\begin{array}{l}0,073 \\
(1,41)\end{array}$ & $\begin{array}{l}0,001 \\
(0,03)\end{array}$ & $\begin{array}{l}0,001 \\
(0,04)\end{array}$ & $\begin{array}{l}-0,010 \\
(-0,20)\end{array}$ & $\begin{array}{l}-0,006 \\
(-0,22)\end{array}$ & $\begin{array}{l}-0,005 \\
(-0,19)\end{array}$ & $\begin{array}{l}-0,012 \\
(-0,44)\end{array}$ \\
\hline Q & $\begin{array}{l}0,065^{* * *} \\
(4,47)\end{array}$ & & & $\begin{array}{l}-0,011 \\
(-0,47)\end{array}$ & & & $\begin{array}{l}-0,035 \\
(-1,26)\end{array}$ & & \\
\hline LOAT & & $\begin{array}{l}-0,037 \\
(-0,51)\end{array}$ & & & $\begin{array}{l}0,038 \\
(0,94)\end{array}$ & & & $\begin{array}{l}0,055 \\
(1,34)\end{array}$ & \\
\hline LOPAT & & & $\begin{array}{l}-0,031 \\
(-0,24)\end{array}$ & & & $\begin{array}{l}-0,151^{*} \\
(-1,72)\end{array}$ & & & $\begin{array}{l}-0,155 \\
(-1,63)\end{array}$ \\
\hline TPO 1 & $\begin{array}{l}-0,269 * * * \\
(-7,90)\end{array}$ & $\begin{array}{l}-0,276 * * * \\
(-8,08)\end{array}$ & $\begin{array}{l}-0,276 * * * \\
(-8,09)\end{array}$ & $\begin{array}{l}-0,292 * * * \\
(-5,80)\end{array}$ & $\begin{array}{l}-0,289 * * * \\
(-5,58)\end{array}$ & $\begin{array}{l}-0,300 * * * \\
(-6,27)\end{array}$ & & & \\
\hline TPO 2 & $\begin{array}{l}-0,417^{* * *} \\
(-10,25)\end{array}$ & $\begin{array}{l}-0,421 * * * \\
(-10,39)\end{array}$ & $\begin{array}{l}-0,422 * * * \\
(-9,90)\end{array}$ & $\begin{array}{l}-0,375^{* * *} \\
(-5,85)\end{array}$ & $\begin{array}{l}-0,372 * * * \\
(-5,69)\end{array}$ & $\begin{array}{l}-0,388 * * * \\
(-6,10)\end{array}$ & & & \\
\hline TPO 3 & $\begin{array}{l}-0,474 * * * \\
(-15,23)\end{array}$ & $\begin{array}{l}-0,487 * * * \\
(-15,41)\end{array}$ & $\begin{array}{l}-0,487 * * * \\
(-15,41)\end{array}$ & $\begin{array}{l}-0,506 * * * \\
(-10,59)\end{array}$ & $\begin{array}{l}-0,503 * * * \\
(-10,25)\end{array}$ & $\begin{array}{l}-0,514 * * * \\
(-11,41)\end{array}$ & & & \\
\hline TPO 5 & $\begin{array}{l}-0,405^{* * *} \\
(-7,78)\end{array}$ & $\begin{array}{l}-0,414 * * * \\
(-8,03)\end{array}$ & $\begin{array}{l}-0,415^{* * *} \\
(-8,01)\end{array}$ & $\begin{array}{l}-0,364 * * * \\
(-4,14)\end{array}$ & $\begin{array}{l}-0,361^{* * *} \\
(-4,03)\end{array}$ & $\begin{array}{l}-0,370 * * * \\
(-4,24)\end{array}$ & & & \\
\hline TPO 6 & $\begin{array}{l}-0,473^{* * *} \\
(-8,49)\end{array}$ & $\begin{array}{l}-0,487 * * * \\
(-8,79)\end{array}$ & $\begin{array}{l}-0,489 * * * \\
(-8,77)\end{array}$ & $\begin{array}{l}-0,491 * * * \\
(-5,84)\end{array}$ & $\begin{array}{l}-0,487 * * * \\
(-5,68)\end{array}$ & $\begin{array}{l}-0,502 * * * \\
(-6,09)\end{array}$ & & & \\
\hline PAYOUT & $\begin{array}{l}-0,0000 \\
(-0,01)\end{array}$ & $\begin{array}{l}-0,0000 \\
(-0,15)\end{array}$ & $\begin{array}{l}-0,0000 \\
(-0,14)\end{array}$ & $\begin{array}{l}0,0000 \\
(0,14)\end{array}$ & $\begin{array}{l}0,0000 \\
(0,33)\end{array}$ & $\begin{array}{l}-0,0000 \\
(-0,16)\end{array}$ & $\begin{array}{l}-0,0000 \\
(-0,07)\end{array}$ & $\begin{array}{l}0,0000 \\
(0,35)\end{array}$ & $\begin{array}{l}-0,0000 \\
(-0,20)\end{array}$ \\
\hline IND 3 & $\begin{array}{l}-0,237 * * * \\
(-5,33)\end{array}$ & $\begin{array}{l}-0,240 * * * \\
(-5,20)\end{array}$ & $\begin{array}{l}-0,240 * * * \\
(-5,17)\end{array}$ & $\begin{array}{l}-0,227 * * * \\
(-2,98)\end{array}$ & $\begin{array}{l}-0,227 * * * \\
(-2,84)\end{array}$ & $\begin{array}{l}-0,233 * * * \\
(-3,18)\end{array}$ & & & \\
\hline IND 8 & $\begin{array}{l}-0,209 * * * \\
(-4,46)\end{array}$ & $\begin{array}{l}-0,200 * * * \\
(-4,41)\end{array}$ & $\begin{array}{l}-0,198 * * * \\
(-4,29)\end{array}$ & $\begin{array}{l}-0,158 * * \\
(-2,19)\end{array}$ & $\begin{array}{l}-0,159 * * \\
(-2,03)\end{array}$ & $\begin{array}{l}-0,158^{* *} \\
(-2,29)\end{array}$ & & & \\
\hline IND 9 & $\begin{array}{l}0,165^{* *} \\
(2,55)\end{array}$ & $\begin{array}{l}0,163^{* *} \\
(2,54)\end{array}$ & $\begin{array}{l}0,163^{* *} \\
(2,54)\end{array}$ & $\begin{array}{l}0,143 \\
(0,83)\end{array}$ & $\begin{array}{l}0,141 \\
(0,81)\end{array}$ & $\begin{array}{l}0,149 \\
(0,85)\end{array}$ & & & \\
\hline IND 10 & $\begin{array}{l}-0,090 * * * \\
(-2,87)\end{array}$ & $\begin{array}{l}-0,076^{* * *} \\
(-2,33)\end{array}$ & $\begin{array}{l}-0,075^{* * *} \\
(-2,21)\end{array}$ & $\begin{array}{l}-0,035 \\
(-0,65)\end{array}$ & $\begin{array}{l}-0,038 \\
(-0,63)\end{array}$ & $\begin{array}{l}-0,036 \\
(-0,77)\end{array}$ & & & \\
\hline IND 12 & $\begin{array}{l}-0,322 * * * \\
(-6,47)\end{array}$ & $\begin{array}{l}-0,319 * * * \\
(-5,99)\end{array}$ & $\begin{array}{l}-0,317 * * * \\
(-5,89)\end{array}$ & $\begin{array}{l}-0,248 * * \\
(-3,24)\end{array}$ & $\begin{array}{l}-0,247 * * * \\
(-3,06)\end{array}$ & $\begin{array}{l}-0,256 * * * \\
(-3,64)\end{array}$ & & & \\
\hline
\end{tabular}


(conclusão)

\begin{tabular}{|c|c|c|c|c|c|c|c|c|c|}
\hline IND 14 & $\begin{array}{l}-0,133^{* * *} \\
(-3,82)\end{array}$ & $\begin{array}{l}-0,138 * * * \\
(-3,86)\end{array}$ & $\begin{array}{l}-0,137 * * * \\
(-3,79)\end{array}$ & $\begin{array}{l}-0,101 * \\
(-1,85)\end{array}$ & $\begin{array}{l}-0,100 * \\
(-1,67)\end{array}$ & $\begin{array}{l}-0,102 * * \\
(-2,09)\end{array}$ & & & \\
\hline IND 15 & $\begin{array}{l}-0,269 * * * \\
(-4,62)\end{array}$ & $\begin{array}{l}-0,251 * * * \\
(-4,32)\end{array}$ & $\begin{array}{l}-0,251 * * * \\
(-4,29)\end{array}$ & $\begin{array}{l}-0,244 * * * \\
(-2,85)\end{array}$ & $\begin{array}{l}-0,246 * * * \\
(-2,72)\end{array}$ & $\begin{array}{l}-0,256^{* * *} \\
(-3,12)\end{array}$ & & & \\
\hline Intercepto & $\begin{array}{l}0,606^{* * *} \\
(5,05)\end{array}$ & $\begin{array}{l}0,631 \text { *** } \\
(5,63)\end{array}$ & $\begin{array}{l}0,636^{* * *} \\
(5,59)\end{array}$ & $\begin{array}{l}0,843 * * * \\
(7,07)\end{array}$ & $\begin{array}{l}0,852 * * * \\
(7,02)\end{array}$ & $\begin{array}{l}0,820 * * * \\
(7,06)\end{array}$ & $\begin{array}{l}0,638 * * * \\
(3,55)\end{array}$ & $\begin{array}{l}0,604 * * * \\
(3,74)\end{array}$ & $\begin{array}{l}0,520 * * * \\
(3,12)\end{array}$ \\
\hline$R^{2}$ & $35,0 \%$ & $33,3 \%$ & $33,3 \%$ & $29,42 \%$ & $29,87 \%$ & $29,98 \%$ & $2,85 \%$ & $1,44 \%$ & $0,97 \%$ \\
\hline Empresas & 152 & 152 & 152 & 152 & 152 & 152 & 152 & 152 & 152 \\
\hline
\end{tabular}

$* * *, * *$ e $*$ correspondem à significância estatística nos níveis de $1 \%, 5 \%$ e $10 \%$, respectivamente.

Nota: A definição das variáveis independentes é apresentada no Quadro. Foram incluídas dummies de ano, omitidas da tabela por limitação de espaço. Também são omitidas as variáveis binárias setoriais (IND) cujos coeficientes não são significantes em nenhuma regressão. Os dados são relativos ao período de 1998 a 2002. Os números entre parênteses indicam a estatística t no caso dos métodos dos Mínimos Quadrados Ordinários (MQO) e de Efeitos Fixos (EF) e indicam a estatística z no caso do procedimento de Efeitos Aleatórios (EA). Os erros-padrão computados para todas as regressões são robustos a heterocedasticidade.

de Himmel berg e outros (1999) de que as empresas com ativos mais difíceis de monitorar (menor proporção de ativos tangíveis) apresentariam maior concentração da propriedade por parte de gestores e/ou empreendedores por possuírem pior proteção ao investidor intrínseca à empresa. N ovamente, os resultados para esta variável não são significantes quando a variável dependente é a concentração do direito de controle.

Conforme discutido anteriormente, a estimação por MQO apresenta uma deficiência potencial por desconsiderar características não observáveis intrínsecas a cada empresa, potencialmente relevantes para explicar a variável dependente, o que pode prejudicar a correta identificação do relacionamento entre as variáveis CON e PROP e seus possíveis determinantes. Para lidar com esta questão, foram realizadas regressões utilizando os métodos de estimação de Efeitos Aleatórios (EA) e de Efeitos Fixos (EF), cujos resultados também constam nas Tabelas 3 e 4 . As estimativas resultantes das regressões por EA mostram uma ausência de significância estatística e redução da magnitude dos coeficientes de todos os possíveis determinantes testados, com exceção dos coeficientes de algumas variáveis binárias referentes ao tipo de acionista controlador e ao setor de atividade da empresa em al gumas das especificações. Com relação a estas dummies, os resultados sugerem inferências similares às comentadas acima. Em particular, destaca-se a menor concentração da estrutura de propriedade das empresas pertencentes aos setores de Comércio (IND 3) e de Petróleo e Gás (IND 12).

Considerando-se que os resultados foram, de forma geral, discrepantes, é importante avaliar os méritos re- lativos dos dois procedimentos descritos até aqui. Uma comparação entre os métodos MQO e EA pode ser feita por meio do teste do tipo Multiplicador de Lagrange de Breusch-Pagan, modificado por Baltagi e Li (1990), que possibilita testar a significância estatística dos efeitos específicos das empresas com base nas estimativas obtidas por EA. O teste tem como hipótese nula:

$$
H_{0}: \operatorname{var}\left(u_{i}\right)=0, i=1,2, \ldots, 161 \text {, }
$$

sendo que $u_{i}$ representa o efeito específico não observável e invariante no tempo da i-ésima empresa da amostra (ver Equação 2), cujo valor esperado éigual a zero, e var( $\left.u_{i}\right)$ é sua variância. A não-rejeição da hipótese nula sugere que os efeitos específicos, também conhecidos como heterogeneidade não observada, não são significantes do ponto de vista estatístico. $O$ resultado do teste rejeitou $\mathrm{H}_{0}$ no nível de significância de 1\% em todas as especificações, sugerindo que a heterogeneidade não observada não dever ser ignorada e, portanto, que as estimações por EA são mais adequadas do que as realizadas pelo método M QO .

$\mathrm{N}$ a seqüência, foram realizadas regressões utilizando-se o procedimento de Efeitos Fixos (EF). Os resultados obtidos com este método de estimação foram similares aos produzidos pelo procedimento de EA, com a ausência de significância estatística dos coeficientes de todos os possíveis determinantes testados. A penas a variável relacionada à tangibilidade das operações da empresa (TANG) mostrou-se significante no nível de 5\%; ainda assim somente quando a variável dependente é a concentração do direito sobre o fluxo de caixa (PROP), invertendo-se o sinal do coeficiente em comparação com o obtido por MQO. 
É possível testar se o método EF é mais adequado do que 0 EA por meio de um teste de Hausman. 0 procedimento consiste na comparação dos dois conjuntos de estimativas. Se as diferenças entre os coeficientes não são significantes estatisticamente, tem-se evidência em favor da consistência do estimador EA. Caso contrário, o estimador EF, cuja consistência depende de suposições menos restritivas, é preferível. Os resultados dos testes de Hausman aplicados às diferentes especificações sugerem que, quando a variável dependente é a concentração do direito de controle ( $C O N$ ), as estimações pelo método EA produzem resultados consistentes. Por outro lado, nas regressões em que a variável dependente é a concentração do direito sobre o fluxo de caixa (PROP), os resultados põem sob suspeita a consistência dos estimadores M Q 0 e $E A$, aconsel hando-se maior cautela quanto às inferências baseadas nestes procedimentos.

Em qualquer caso, pode-se inferir, com base nas estimativas estatisticamente mais robustas produzidas por meio dos procedimentos de Efeitos Aleatórios e de Efeitos Fixos, que não há evidências suficientes nos dados de que as concentrações do direito sobre o fluxo de caixa e do direito de controle das empresas analisadas sejam determinadas pelas variáveis su geridas pel os estudos precedentes. Ao contrário, os resultados são consistentes com a hipótese de que as variáveis CON e PROP podem ser tratadas como aproximadamente exógenas, sendo mais influenciadas por idiossincrasias e pela história de cada empresa do que por padrões previsíveis relacionados a suas características observáveis. N atural mente, tais inferências estão condicionadas às limitações do estudo, dentre as quais se destacam o possível viés de seleção introduzido pelo descarte das empresas com ações ilíquidas ou com dados incompletos e deficiências das definições operacionais dos regressores testados como determinantes potenciais.

\section{CONSIDERAÇÕES FINAIS}

0 objetivo principal da pesquisa foi investigar se os atributos corporativos e setoriais sugeridos por Demsetz e Lehn (1985) e por Himmelberg e outros (1999) são capazes de explicar a concentração acionária dos controladores das companhias abertas brasileiras ou se sua estrutura de propriedade e controle é aproximadamente exógena. Especificamente, foram testados os seguintes determinantes potenciais como regressores contra o percentual de ações ordinárias (CON) ou o percentual total de ações (PROP) em posse do(s) acionista(s) controlador(es) : N atureza da operação (TAN G ); Porte da empresa $(\log (\mathrm{REC}))$; Nível do fluxo de caixa livre (FCL / REC); Taxa de investimento da empresa (I / K); Risco Idiossincrático (IDIOS); Desempenho da empresa: Q de Tobin (Q), Lucro operacional sobre ativo total (LOAT) e Lucro operacional próprio sobre ativo total (LOPAT); Identidade do acionista controlador (TIPO); e Setor de Atuação (IND).

Utilizando o método dos Mínimos Quadrados Ordinários (M Q O) aplicado a um painel (desbal anceado) de empresas com dados entre 1998 e 2002, as proxies para o nível do fluxo de caixalivre epara a taxa de investimento apresentaram uma relação positiva e significante no nível de $5 \%$ ou $10 \%$ com a concentração do direito de controle e também com a concentração do direito sobre o fluxo de caixa. Também as variáveis $Q$ de Tobin, tipo do acionista controlador, setor de atuação da empresa, tamanho e tangibilidade revelaram-se ocasional mente significativas, dependendo da especificação adotada.

Não se obteve, entretanto, salvo poucas exceções em al gumas especificações, significância estatística para o coeficiente de qual quer variável explicativa após a aplicação dos procedimentos de Efeitos A leatórios (EA) e de Efeitos Fixos (EF), mais adequados do que o método M QO para o problema em questão. As principais exceções foram os coeficientes de algumas dummies setoriais e de Tipo do Acionista Controlador, com coeficientes estimados pelo método EA. Em especial, observa-se que as empresas pertencentes aos setores de Comércio (IND 3) e de Petróleo e Gás (IND 12) apresentaram estrutura de propriedade substancialmente mais pulverizada do que a média. Também se destaca que as empresas estatais $\left(\mathrm{TIPO}_{6}\right)$ e de controle familiar $\left(\mathrm{TIPO}_{3}\right.$ ) apresentam concentração dos direitos sobre o fluxo de caixa do negócio significativamente abaixo da média, refletindo a emissão de quantidade substancial de ações sem direito a voto.

Em resumo, o resultado principal da pesquisa é que os atributos corporativos discutidos por Demsetz e Lehn (1985) e Himmelberg e outros (1999) como possíveis determinantes da estrutura de propriedade não parecem influenciar a concentração do direito de controle e do direito sobre o fluxo de caixa nas companhias abertas brasileiras, ressalvando-se as limitações do estudo, em particular deficiências das definições operacionais das variáveis e um possível viés de seleção introduzido pelos critérios de amostragem.

As conclusões da pesquisa diferem das reportadas por Himmelberg e outros (1999), baseadas em dados norteamericanos, e das reportadas por Araújo Filho e outros (2003) a partir de dados brasileiros. Araújo Filho e outros 
(2003) utilizaram, porém, métodos diferentes de investigação. Os resultados aqui reportados são compatíveis com aqueles obtidos por O kimura (2003), que não encontrou evidências da presença de endogeneidade nas variáveis de estrutura de propriedade no Brasil.

Os resultados da pesquisa revelam, em primeiro lugar, a importância do método adotado para a estimação dos coeficientes. A aplicação exclusiva do método MQO levaria à conclusão de que al gumas das variáveis testadas influenciam a estrutura de controle e de propriedade das empresas. Entretanto, os resultados são diferentes quando o método de estimação considera explicitamente características específicas não observadas (e invariantes no tempo) das empresas, as quais são provavel mente relevantes, conforme evidenciam as análises de diagnóstico. Desta forma, a aplicação exclusiva do M QO poderia conduzir a conclusões inapropriadas.

Em segundo lugar, a não-significância dos candidatos a determinantes da estrutura de propriedade sugere que as variáveis $C O N$ e PROP podem ser adequadamente caracterizadas como aproximadamente exógenas. Com base resultados aqui reportados e de pesquisas anteriores como, por exemplo, Claessens e outros (2002), pode-se especular que, particularmente em países emergentes, com mercados de capitais pouco desenvolvidos, a estrutura de propriedade é provavelmente mais influenciada pelo ambiente institucional, pela história das empresas e por suas idiossincrasias do que por atributos corporativos observáveis, como aqueles considerados neste estudo. Esta evidência, por sua vez, coaduna-se com a hipótese de exogeneidade da estrutura de propriedade implícita ou explicitamente adotada pela maior parte dos trabal hos que investigam sua influência sobre o desempenho corporativo. Portanto, esta pesquisa contribui indiretamente para a discussão acadêmica sobre a existência ou não de uma estrutura de propriedade ideal capaz de maximizar o valor das empresas.

\section{REFERÊNCIAS}

ARAÚJO FILHO, L. F. C.; RAMOS DE SOUZA, H.; CARMONA, C. M. U. A estrutura de propriedade das empresas de capital aberto no Brasil e os fatores determinantes da concentração acionária. In: Encontro Brasileiro deFinanças, 3ํ, 2003, São Paulo. Anais [...] Disponível em: «tttp://www. sbfin.org.br/>. Acesso em 10 jul. 2004.

BALTAGI, B.H.; LI, Q. A Lagrange multiplier test for the error components model with incomplete panels. Econometrics Review, v. 9, n. 1, p. 103-107, 1990.
BREUSCH, T.; PAGAN, A. A simple test for heteroscedasticity and random coefficients variation. Econometrica, v. 47, p. 1287-1294, 1979.

CAMERON, A.C.; TRIVEDI, P.K. The information matrix test and its applied alternative hypothesis. Working Paper, 1990.

CHUNG, K.; PRUITT, S. A simple approximation of Tobin's Q. Financial Management, v. 23, n. 3, p. 70-74, Autumn 1994.

CLAESSENS, S.; DJANKOV, Simeon; FAN, J. P.H.; LANG, Larry H.P. Disentangling the incentive and entrenchment effect of large shareholdings. The Journal of Finance, v. 57, n. 6, p. 2741-2771, Dec. 2002.

DEMSETZ, H.; LEHN, K. The structure of corporate ownership: causes and consequences. Journal of Political Economy, v. 93, n. 6, p. 1155-1177. Dec. 1985.

HERMALIN, B.; WEISBACH, M. The effect of board composition and direct incentives on firm performance. Financial Management, v. 21, n. 4, p. 101-112, 1991.

HIM M ELBERG, C; HUBBARD, G.; PALIA, D. Understanding the determinants of managerial ownership and the link between ownership and performance. Journal of Financial Economics, v. 53, p. 353-384, 1999.

JENSEN, M. Agency costs of free cash flow, corporate finance and takeovers. American Economic Review, v. 76, p. 323-329, May 1986.

LA PORTA, R.; SHLEIFER, A.; LOPEZ-DE-SILANES, F. Corporate ownership around the world. Journal of Finance, v. 54, p. 471-517, 1999.

LA PORTA, R.; SHLEIFER, A.; LOPEZ-DE-SILANES, F.; VISHNY, Robert. Law and finance. Journal of Political Economy, v. 106, p. 1113-1155, 1998.

LA PORTA, R.; SHLEIFER, A.; LOPEZ-DE-SILANES, F.; VISHNY, Robert.. Investor protection and corporate governance. Journal of Financial Economics, v. 58, p. 3-27, Oct. 2000.

LEAL, R.; VALADARES, S. O wnership and control structure of Brazilian companies. Unpublished working paper. Disponível em: <http://www. coppead.ufrj.br/ricardoleal/publications.html>. Acesso em 18 jul. 2002.

MCCONNEL, J.; SERVAES, H. Additional evidence on equity ownership and corporate value. Journal of Financial Economics, v. 27, p. 595-612, 1990.

MORCK, R.; SHLEIFER, A.; VISHNY, R. W. Management ownership and market valuation: an empirical analysis. Journal of Financial Economics, 20, p. 293-315. 1988.

OKIMURA, R. T. Estrutura de propriedade, governança corporativa, valor e desempenho das empresas no Brasil. 2003. 120p. Dissertação de Mestrado, Faculdade de Economia, Administração e Contabilidade da Universidade de São Paulo, São Paulo, 2003. 


\section{Artigo recebido em 22.05.2005. A provado em 31.01.2008.}

\section{Alexandre Di Miceli da Silveira}

Professor da Faculdade de Economia, Administração e Contabilidade, Universidade de São Paulo Doutor e Mestre em Administração de Empresas (Finanças) pela Faculdade de Economia, Administração e Contabilidade, Universidade de São Paulo

Interesses de pesquisa nas áreas de governança corporativa e estrutura de propriedade

E-mail: alexfea@usp.br

Endereço: Av. Luciano Gual berto, 908, FEA/USP, Prédio 3, Sala 239, São Paulo-SP, 05508-900

\section{Lucas Ayres B. de C. Barros}

Professor da Faculdade de Ciências Econômicas, Contábeis e Administrativas, Universidade Presbiteriana Mackenzie

Doutor em Administração de Empresas pela Faculdade de Economia, Administração e Contabilidade, Universidade de São Paulo

Interesses de pesquisa nas áreas de finanças, valor da empresa, estrutura de capital, modelagem econômica, finanças comportamentais e finanças estocásticas

E-mail: lucasayres2002@yahoo.com.br

Endereço: Rua Florália, 103, Jardim Atibaia, São Paulo - SP, 05451-130

\section{Rubens Famá}

Professor da Faculdade de Economia, Administração e Contabilidade, Universidade de São Paulo Doutor em Administração de Empresas pela Faculdade de Economia, Administração e Contabilidade, Universidade de São Paulo

Interesses de pesquisa nas áreas de finanças corporativas, incluindo avaliação de investimentos, custo de capital e estrutura de capital

E-mail: rfama@usp.br

Endereço: R. Morás, 656, Ap. 5, Vila Madalena, São Paulo - SP, 05434-020 